\title{
Looking in From the Outside: The Case of the Excluded Self-Publisher
}

\author{
Liz Poliakova \\ York \& Ryerson Joint Graduate Program in Communication \& Culture \\ York University
}

\begin{abstract}
A significant portion of books on Amazon are self-published using Kindle Direct Publishing. Self-publishers are given an opportunity to share their work with the world with a few clicks of their mouse. However, traditional publishing infrastructures are not as welcoming to the self-publisher. This paper performs a discourse analysis of government funding frameworks available to workers in the Canadian publishing industry. Through the analysis stage, the study finds that the selfpublisher is ineligible to apply for funds and grants from the government both on the provincial and the federal levels. The self-publishing business model is not recognized as a legitimate one and is often equated with vanity publishing, which comes with a stigma. Furthermore, traditional publishing industry workers act as gatekeepers who also exclude the self-publisher from the conversation around the changing landscape of the Canadian publishing industry. Even though the selfpublisher should be recognized as a legitimate worker of the cultural industries, they are not acknowledged as such both by government officials who distribute grants and traditional publishers. This study adds to the limited scope of research conducted on self-publishing in order to break the boundaries that self-publishers encounter. The study concludes with recommendations to assess the process of the distribution of government funds and grants in order to incorporate the changing practices of the cultural industries and incorporate new business models such as self-publishing.
\end{abstract}

\section{Keywords}

Publishing, self-publishing, government frameworks, funding frameworks. 
When David Chilton first self-published The Wealthy Barber it sold only 12,000 copies (McGugan, 2015). However, over the years the book was purchased over 2 million times (MacDonald, 2011). Even though Chilton's debut work can be considered a best-selling sensation, it has never been nominated for a Canadian literary award or prize. Self-publishers are usually excluded from the traditional publishing industry by being barred from award nominations in addition to being ineligible for government funding that is given to workers of the conventional book trade. As displayed by Chilton's success story, self-publishers can contribute substantially to the publishing industry in Canada and should be given equal opportunities as traditional publishers.

For the purpose of this study a self-publisher will be defined as someone who finds their own consumers directly, takes on all the financial burdens of the project related to each stage of the production-distribution-consumption cycle, which can include hiring others for such jobs as editing and distribution. The novel form of self-publishing that is discussed in this paper refers to digital self-publishing practices, which include the production of eBooks and the employment of online distribution methods. On the other hand, the traditional publisher will be defined as someone who works with multiple authors simultaneously, owns the rights to their work, and fully subsidizes the project. Traditional presses are in full control of the production, distribution, and marketing stages where the authors' opinions and preferences are secondary. The major disparity between the two business models is the fact that the production team has more agency in the process of publication, distribution, and marketing, whereas the self-publishers have full agency over these stages. With the introduction of novel distribution methods, such as the purchase of products online, the author no longer needs the publisher to be their link to the reader. Therefore, the conventional publishers can no longer be recognized as the only gatekeepers who provide access to consumers. The infrastructure of the publishing industry is changing with new digital publishing practices changing the roles of the workers in the book trade.

This paper performs a discourse analysis, which aims to deliver that some government funding models should be re-examined in order to incorporate novel business models through the example of the excluded self-publisher. Discourse analysis is associated with social interactions: "social reality is produced and made real through discourses, and social interactions cannot be fully understood without reference to the discourses that give them meaning" (Phillips and Hardy, 2002: 3). This type of data analysis is utilized in order to explore the relationship between the self-publisher and the traditional publishing sector through observing the language the government frameworks employ to describe "legitimate" candidates for their 
funds and grants. The study concludes that the self-publisher is omitted from the government frameworks designed to aid actors of the publishing industry, which creates inequalities between new and traditional business models. The study concludes by suggesting some changes, which can be made to the government funding policies in order for the self-publisher to become a legitimate member of the publishing industry.

\section{The Canadian Book Trade in Historical Perspectives}

The Canadian government has had an active role in the function of the Canadian cultural industries since 1957 with the founding of the Canada Council for the Arts; in 1972 the federal government started providing funds and loans to publishers directly (Dewar, 2017). The role of the government in the cultural industries is an important one and is emphasised by a number of political economy scholars (Downing, 2014; Golding and Murdock, Garnham, 2014; 1996; McChesney, 2000; Mosco, 2009). However, no active research is being conducted on the government's role in the Canadian publishing sector and how new business models such as selfpublishing can be successfully incorporated into the Canadian book trade. This study aims to open future discussions on the role of the self-publisher in the changing landscape of the Canadian publishing industry and highlight some issues present in government funding frameworks.

Vincent Mosco (2009) contends that creating "social policies and programs to protect the economic existence of social acts" is an important role of the government in order to have a democratic space, not influenced by capitalistic values of business conglomerates (p. 147). This can be displayed in the significance of having "Free Spaces" that take the shape of independent presses or public broadcasting networks (ibid). In Canada there are no public divisions or any open access platforms for writers to create and distribute their literary projects. Authors who do not want to pursue a traditional publishing career have to resort to third-party foreign online publishing websites (e.g. Amazon, Smashwords, etc.). However, in order for cultural diversity to flourish there has to be a balance between corporations driven by capital and the public division (Golding and Murdock, 1996, p.17). Government funding programs can potentially prompt the development of open access spaces that bypass traditional methods of production, which can create a more diverse environment. The current government funding available has mostly helped the already established actors of the traditional publishing industry. This is an issue because the corporate world of book production (the gatekeepers) often limits the entrance of new business models into the system. 
In a historical perspective, the distinction between traditional presses and presses founded by authors have been blurred in the Canadian publishing sector. There was no evident stigma attached to writers who would go on to establish their own publishing houses; in contrast, they would be described as valuable additions to Canadian literary culture (Lorimer, 2012; MacSkimming, 2007). However, research on the Canadian book trade does not link the author-turned-publisher to the practice of self-publishing in any way. During the inception of the Canadian publishing industry many writers of poetry would start a publishing house to produce their own work. For instance, House of Anansi, which still operates today, was established by two writers: Dennis Lee and Dave Godfrey. The earliest work of the press was Lee's own poetry (Shoesmith, 2013: 10-11). Nevertheless, the term "self-publishing" is absent from studies conducted on the Canadian publishing industry. Furthermore, there are very few contemporary studies conducted on the Canadian self-publishing sector in general (Olson, 2014; Thomlison and Belanger, 2015); and there are no studies specifically outlining how new business models, such as digital selfpublishing, are being incorporated into the Canadian book trade. This study aims to fill this void in order to bring self-publishing into the conversation around the changing practices in the publishing industry.

\section{Federal Funding}

The Canada Book Fund (CBF) and the Canada Council for the Arts programs are the largest sources of funding available to workers of the publishing industry. Approximately $\$ 39$ million is allocated to publishers and publishing programs by the CBF, followed by $\$ 11$ million distributed by the Canada Council for the Arts (Nawotka, 2018). The Canada Book Fund was introduced in 2009 and came into effect in 2013-2014 by replacing the Book Publishing Industry Development Program (BPIDP) (Lorimer, 2012, p. 174). The following section of the research draws on data collected from the CBF Application Guidelines from 2013-2019, in addition to the Cultural Industries Cluster Evaluation Report (Department of Canadian Heritage, 2014) in order to highlight some issues in the wording of the funding frameworks, which ultimately exclude new business models.

All the Application Guidelines analyzed for this study state that the main goal of the CBF is to encourage the visibility of Canadian-authored books through tools such as marketing and to strengthen "the infrastructure and efficiency" of the Canadian publishing sector (Canada, 2019a; Canada Book Fund, 2017, p. 2; Canada Book Fund, 2016, p. 2; Canada Book Fund, 2015, p. 2; Canada Book Fund, 2012, p. 2). Conversely, when the documents are searched for key terms that relate to cultural goals ("culture" and "heritage"), they do not appear in the program framework. There are 
no objectives developed to advance innovative cultural projects or practices, such as incorporating new business models (self-publishing, online distribution systems, etc.) into the book trade system. However, the guidelines specifically underscore that the objective to strengthen the current publishing infrastructure can be achieved through investing in projects and presses that already display commercial success (Canada Book Fund, 2017, p. 4; Canada Book Fund, 2016, p. 4; Canada Book Fund, 2015, p. 4; Canada Book Fund, 2012, p. 2).

An analysis of the Cultural Industries Cluster Evaluation Report further accentuates that the CBF is primarily interested in the economic potential of the Canadian book trade (Department of Canadian Heritage, 2014, p. 39). The report emphasizes that "economic stimulus" (Department of Canadian Heritage, 2014, p. 11) is an essential factor in the stabilization of the publishing industry. Arguably, there is no incentive on behalf of the CBF to invest into new publishing practices but to specifically foster already developed traditional presses and their infrastructures that relate to the cycle of production, distribution, and consumption.

The goal of supporting aspects of the industry that are economically viable is not a new phenomenon. This practice can be traced back to the first program developed by the government in the 1970s, the Canadian Book Publishing Development Program (CBPDP) and later the Book Publishing Industry Development Program (BPIDP). The CBPDP distributed the majority of the grants directly to publishers; $61 \%$ of the funding went to only five of the biggest publishing houses, with the rest of the grants given out to less commercially successful presses (Lorimer, 2012, p. 100). Even though the amount of funding left over was still a substantial amount, there was a large number of small presses applying for these grants, which meant that each individual press would get much less funding than the top five publishing houses. Therefore, there were boundaries created from the inception of these government programs, which excluded new businesses and supported the function of the established traditional presses. The BPIDP was also not an exception to this practice of fostering financially viable presses because the program's goal was to combat low profitability (Department of Canadian Heritage, 2008, p. 44).

The CBF has specific eligibility guidelines, which state that author subsidized projects are not eligible to receive grants and funding (Canada, 2019b). However, none of the eligibility criteria specifically state that "self-publishers" are not qualified to apply. Based on the wording of the criterion, there appears to be a stigma attached to works that are subsidized by the author, which can be read as selfpublished or as vanity publications. Conversely, vanity publishing and selfpublishing are two separate practices. The main distinction between the two is that 
vanity publishers do not have the intention to sell the books because their main revenue comes directly from the author's pocket (Vanity Publishing, 2009). Therefore, vanity presses do not strive to employ the highest standards when creating the finished product when the self-publisher's main goal is to sell the product by creating a quality item that is marketable (Samson, 2018). Moreover, vanity presses provide packaged deals with no choice of professionals who create the final product such as editors and graphic designers; these packages are overpriced, and many authors end up in debt (Silver, 2017; Samson, 2018). On the other hand, the self-publisher is able to hire workers on a freelance basis and is in full control of who is aiding in the creation of the final product. Therefore, it must be recognized that vanity publishing is not the same as self-publishing. In the wording of the frameworks the two practices are not differentiated in any way but grouped together as similar practices that are not eligible for funding.

The CBF is not the only source of federal funding that aids the workers of the publishing industry which excludes self-publishers. The Canada Council for the Arts grants funding to individual projects as well as organizations. The distribution of the fund is based on a peer review method that evaluates the candidates on a case-bycase basis. However, the debate centered around funding projects that are economically successful versus culturally impactful ones has not escaped this government program either. Funding bodies such as the Canada Council for the Arts often need to display some economic arguments that justify the cultural products being funded such as "job creation, tourism and increased tax revenue" (Brault, 2005, p. 57). However, the council still predominantly funds artistic projects over commercial ones, which is displayed through their eligibility criteria that includes fiction, poetry, graphic novels, literary non-fiction, drama, children's literature (Canada Council for the Arts, 2020). Conversely, titles that the author contributes to financially are ineligible for funding (ibid), which directly excludes self-publishers. Once again, it must be noted that the wording of the document does not necessarily state that "selfpublishers" are ineligible. There is a gray zone created by these frameworks that do not acknowledge the existence of this new publishing practice. Nonetheless, new workers of the publishing industry are excluded due to the vague wording used in the eligibility requirements.

The funding frameworks from the CBF and the Canada Arts Council emphasize the issue of how the government often primarily focuses on promoting the economic aspects of the cultural industries. The government's economic objectives often overpower the sociocultural ones. Once cultural industries are recognized as businesses that produce products for consumption, it is difficult to recognize them as separate entities in the capitalist marketplace (Raboy, Bernier, Sauvageau, \& At- 
kinson, 1994). In theory, it is logical to support businesses that are financially viable. However, the potential problem with that would be the lack of diversity of content. As stipulated by Golding and Murdock (1996) capital should not be the only factor in the decision of what cultural products are produced in order for diversity to develop (p.17).

To conclude, the federal portion of the funding programs available support and favour projects that display financial promise. Furthermore, the term "selfpublishing" is not present in any of the documents under investigation. The eligibility criteria uses vague wording that excludes self-publishers without mentioning the actual term. Arguably, this signals that the practice of self-publishing is not recognized as a legitimate one in the publishing sector.

\section{Provincial Funding}

In order to understand whether self-publishers are only experiencing this exclusion on the federal level, the research analyzes the funding frameworks on the provincial level as well. All the art councils, with the exception of the Nunavut Arts and Crafts Council, have websites that display the different guidelines pertaining to the types of funding available to presses and writers. At the time of the study, The Nunavut Arts and Crafts Council website was under renovation, and no information on funding was available. The next section of the paper confirms that there are boundaries which self-publishers have to face not only on the federal but also on the provincial level in terms of their eligibility for funding programs.

Through conducting a discourse analysis of the frameworks, the theme of a "gray zone" in the eligibility criteria is also present in the guidelines of the provincial councils, where projects subsidized by the author are ineligible for funding. For example, Alberta Foundation for the Arts states that the following are not eligible for funding: "privately printed, self-published, and vanity press publications...print-ondemand or shared cost publications" (Alberta Foundation for the Arts, 2018). The role of the traditional gatekeeper of the publishing industry is reinforced in these guidelines, which do not accept the fact that the production, distribution, and marketing of a product can be done by a single person through utilizing freelance workers or online tools. Similarly, the Arts Council of British Columbia provides a funding package, Operating Assistance for Book Publishers, which does not fund "selfpublished books and books to which the author has made a financial contribution towards" (British Columbia Arts Council, 2018, p. 10). Another program supported by British Columbia Arts Council, Professional Project Assistance, does not provide funds towards for-profit projects (British Columbia Arts Council, 2019, p. 4-5). Man- 
itoba Art Council states that ineligible projects comprise of: "commercial production work in any discipline" and "self-publication" (Manitoba Arts Council, 2018, p. 11). Even though some art councils state that they support the collaboration of the different actors of the publishing industry, the guidelines still state that self-published work is not eligible for funding (Ontario Arts Council, 2020). Arts Nova Scotia's funding guidelines state that $75 \%$ of titles produced by the press must be by authors "other than principals in the company" (Arts Nova Scotia, 2018, p. 1). Moreover, some art councils do not fund all the stages of the production, distribution, marketing cycle. Northwest Territories Arts Council excludes projects that need funding for marketing or distribution purposes (NWT Arts Council, 2019, p. 6). Additionally, commercial publishing projects and projects that present "sole financial gain of an artist" are ineligible (NWT Arts Council, 2019, p. 5).

Nonetheless, there are a few art councils that do support the work of the selfpublisher, which signals a change in the publishing industry. New Brunswick Arts Board provides grants for new and emerging artist, which include individuals who "published at least one book with a professional publishing house or at least 10 poems or at least 3 short stories or 3 works of literary non-fiction...or at least one selfpublished book that successfully demonstrates commercial intent" (New Brunswick Arts Board, 2019). Similarly, Newfoundland and Labrador Arts Council provides funding through its Professional Project Grants Program, which supports an individual who has "copyright in his or her own work and has received royalty or residual payment based on that copyright" (Newfoundland and Labrador Arts Council, 2019). Therefore, there are some art councils that do provide support to individuals who want to self-publish and not take the traditional publishing route. The Art Councils of Saskatchewan, Newfoundland and Labrador, Prince Edward Island, and Yukon were not recognized to support or exclude the self-publisher.

Through this analysis it becomes evident that half of the art councils analyzed (Alberta, British Columbia, Manitoba, Ontario, North West Territories, Nova Scotia) specifically emphasize in their guidelines that they do not distribute grants to self-publishers or projects that are subsidized by the author. Arguably, this depicts that new business models are recognized but are deliberately excluded, while traditional publishing practices are promoted. On the other hand, the two art councils that do support all forms of production, self-published or not, are examples of how the self-publisher can potentially become incorporated into the publishing industry funding system successfully. 


\section{Reports from the traditional publishing industry}

The next section explores reports published by key workers of the publishing industry in order to understand whether the boundaries that self-publisher encounter also stem from the traditional publishing sector. This study investigates a report issued by the Association of Canadian publisher (ACP), which represents around 115 presses and is a major association for traditional publishers in Canada (Association of Canadian Publishers, 2019). Another document is published by Association Nationale des Éditeurs de Livres (ANEL) that specifically acts on behalf of Frenchlanguage presses. Lastly, this study also examines a report issued by members of the traditional publishing sector that met during a think-tank session in order to compile recommendations for the publishing industry in Canada. The study analyzes the objectives each report emphasizes and whether the self-publishing business model is mentioned in terms of the changes impacting the publishing industry.

The report published by the ACP highlights such issues as the lack of diversity in the publishing industry (Association of Canadian Publishers, 2015, p. 3) and the need for reallocation of funds towards the distribution and marketing stages of the publishing cycle (Association of Canadian Publishers, 2015, p. 7). Even though the report recognizes that the current infrastructure of the publishing sector is due for an upgrade, there is no mention of new business models (such as online distribution methods) that would be able to support these changes. Additionally, there is no mention of the self-publishing business model and how this phenomenon is becoming more mainstream. For instance, Bowker published a report, which revelled that over one million self-published books were registered in 2017 (Bowker, 2018).

ANEL is another publishers' association, which discussed related objectives as the ACP for the publishing industry in their 2017 report. Similarly, the issue of distribution of content has come up in the document (Association Nationale des Éditeurs de Livres, 2017, p. 4). However, there are no specific changes indicated in the report on how to proceed with new distribution models and who they should be available to. Another objective promoted by ANEL is the adoption of new tools and innovations by traditional publishers such as print-on-demand technology (Association Nationale des Éditeurs de Livres, 2017, p. 4). Arguably, this further cements the role of the traditional publishers as the only legitimate actors of the industry since they are promoted to host the print-on-demand technology, and there is no indication as to who can access it. Analogously to the report published by the ACP, there is no mention of self-publishing. 
The More Canada report was written by twenty-nine professionals from the publishing industry in order to assess the state of the Canadian book trade. Similar to the two previous documents, the report outlines the issues with the accessibility and distribution of Canadian content, which was discovered through the use of language in the report (Canadian Publishers Hosted Software Solutions, 2018, p.11, 14, $17,25)$. However, the self-publishing business model and the role of self-publishers in the Canadian book trade is not mentioned either.

BookNet Canada produced a report asking respondents from the publishing sector a series of opinion-based questions that relate to the future of the publishing industry. The top two answers to what can possibly disrupt the publishing trade were "self-publishers" and "new business models." Both of these answers were chosen by $30 \%$ of respondents (BookNet Canada, 2017, p. 33). It can be observed through this response that traditional publishers do not support the self-publishing business model. The self-publishers are mostly invisible to the workers of the traditional publishing sector, but when they are recognized they hold a place in the margins seen as the disturbers. None of the reports produced by workers of the traditional publishing industry talk about novel business models of book production (eBooks) or distribution (digital distribution methods), indicating that the novel self-publishing business model is excluded from the conversation indefinitely.

\section{Conclusion}

After analyzing a number of government funding programs and reports published by workers of the publishing industry, this study aims to highlight that as new and unconventional members of the cultural industries become more visible, there are challenges present that should be addressed. Arguably, traditional actors of the different cultural industries are often valued to a higher degree than new business models, which is problematic. As it was evident in the different reports published by the traditional workers of the publishing sector, the self-publisher is not recognized as a member and is not included in the conversation around the changing infrastructure of the book trade industry.

The following section of the paper proposes a number of recommendations to the current structure of the funding models aimed at the publishing industry that should incorporate novel business models. A short-term goal would be geared at incorporating self-publishers into the system at the provincial level. As it was discussed, some provincial art councils do not restrict the self-publisher from applying for funding and grants. Therefore, there is a place for the self-publisher in the government funding ecosystem. By lifting the boundaries at the provincial level for all 
provinces and territories, self-publishers can start to be recognized as legitimate actors of the publishing industry.

A long-term goal would include the re-distribution of the Canada Book Fund in order to develop the current infrastructure that deals with production and distribution channels that would be open not only to traditional presses but also to new business models such as self-publishers. These new infrastructures can be modeled on platforms such as Amazon that provide self-publishers and conventional presses the possibility to upload books for sale without gatekeepers. Furthermore, the CBF can draw from other government programs in terms of its distribution practices such as The Canada Arts Council, which distributes its grants based on a peer review process. A similar practice can be employed for the Canada Book Fund by introducing different tiers or stages that an applicant has to go through. This process would be rigorous, but it would also be more inclusive by opening up the eligibility criteria.

The publishing culture is changing, which is displayed by the development of new infrastructures such as online book creation and distribution. The selfpublisher is a part of this change and should be recognized as a legitimate member of the Canadian publishing industry both by the government and the traditional publishers, which can be done through opening up access to grants and funding. 


\section{References}

Alberta Foundation for the Arts, (2018). Literary individual project funding. Retrieved from: https://www.affta.ab.ca/funding/find-funding/literary-individual-project-funding

Arts Nova Scotia, (2018). Program guidelines. Retrieved from: https://artsns.ca/sites/default/files/pdfs/project grants for publishing guidelines.pdf

Association Nationale des Éditeurs de Livres, (2017). The government of Canada's pre-budget consultations for 2018. Retrieved from: http://www.ourcommons.ca/Content/Committee/421/FINA/Brief/BR9073396 /br-external/AssocNationaleDesÉditeursDeLivres-e.pdf

Association of Canadian Publishers, (2019). About. Retrieved from: https://publishers.ca/about/

Association of Canadian Publishers, (2015). Canada's book publishers: Telling our stories, growing our economy. Submission to Ontario's culture strategy. Retrieved from: https://publishers.ca/wp-content/uploads/2017/02/2015-ACP-ONCultureStrategy-2.pdf

BookNet Canada. (2018). The state of digital publishing in Canada 2017. Retrieved from: https://www.booknetcanada.ca/state-of-digital-publishing

Brault, S. (2005). The arts and culture as new engines of economic and social development. Policy Options, 26(3), 56-60.

British Columbia Arts Council, (2018). Program guidelines - 2018/19 operating assistance program - book publishers. Retrieved from: http://www.bcartscouncil.ca/documents/guidelines/pdfs/Operating\%20Assist/ 10-009\%20GLs Book\%20Publishers Aug2018 FINAL.pdf

British Columbia Arts Council, (2019). Program guidelines 2019/20 professional project assistance program literary arts. Retrieved from:

http://www.bcartscouncil.ca/documents/guidelines/pdfs/Project\%20Assistanc e/20-014 GLs Project\%20Assistance Literary\%20Arts Feb\%202019 FINAL.pdf

Canada. Department of Canadian Heritage, (2019a). Canada Book Fund: Application guidelines - support for organizations. Retrieved from:

https://www.canada.ca/en/canadian-heritage/services/funding/bookfund/support-organizations/application-guidelines.html

Canada. Department of Canadian Heritage, (2019b). Canada Book Fund: application guidelines - support for publishers: publishing support. Retrieved from: https://www.canada.ca/en/canadian-heritage/services/funding/bookfund/publishing-support/application-guidelines.html 
Canada Book Fund, (2017). Canada Book Fund - support for organizations - application guide - 2017-2018. Retrieved from:

http://publications.gc.ca/collections/collection 2017/pch/CH41-31-2017eng.pdf

Canada Book Fund, (2016). Canada Book Fund - support for organizations application guide 2016-2017. Retrieved from:

http://publications.gc.ca/collections/collection 2015/pc-ch/CH41-31-2016eng.pdf

Canada Book Fund, (2015). Canada Book Fund-support for organizations application guide 2015-2016. Retrieved from: http://publications.gc.ca/collections/collection 2015/pc-ch/CH41-31-2015eng.pdf

Canada Book Fund, (2012). Canada Book Fund 2013-2014 - application guide - support for organizations. Retrieved from:

http://publications.gc.ca/collections/collection 2012/pc-ch/CH41-31-2013eng.pdf

Canada Council for the Arts (2020). Eligible and ineligible titles. Retrieved from: https://canadacouncil.ca/glossary/eligible-titles

Canadian Publishers Hosted Software Solutions, (2018). More Canada: Increasing Canadians' awareness and reading of Canadian books. Retrieved from: https://www.morecanadareport.ca

Department of Canadian Heritage, (2014). Cultural industries cluster evaluation Canada Music Fund and Canada Book Fund for the period from 2007-08 to 2011-12. Retrieved from: http://publications.gc.ca/collections/collection 2014/pcch/CH44-152-2014-eng.pdf

Department of Canadian Heritage, (2008). Summative evaluation of the Book Publishing Industry Development Program. Retrieved from:

http://publications.gc.ca/collections/collection 2016/pch/CH7-46-2008-eng.pdf

Dewar, E. (2017). How Canada sold out its publishing industry. The Walrus. Retrieved from: https://thewalrus.ca/no-one-blinked/

Downing, J. (2014). Media ownership, concentration and control: The evolution of debate. In J, Wasko, G. Murdock \& H. Sousa (Eds.) The Handbook of Political Economy of Communication. Oxford: Blackwell Publishing.

Garnham, N. (2014). “The Political Economy of Communication Revisited.” In Wasko, J., Murdock, G., Sousa, H. The Handbook of Political Economy of Communications. Malden, MA: Wiley-Blackwell. 
Golding, P. \& Murdock, G. (1996). Culture, Communications, and Political Economy. In J. Curran \& M. Gurevitch (Eds.) Mass Media and Society. London: Arnold.

Lorimer, R. (2012). Ultra libris: Policy, technology, and the creative economy of book publishing in Canada. Toronto: ECW Press.

Manitoba Arts Council. (2018). Manitoba Arts Council's General Guidelines. Retrieved from: https://artscouncil.mb.ca/wpcontent/uploads/2018/12/General Guideline V02 ES.pdf

MacDonald, L. (2011). Reviewed: The wealthy barber returns. Canadian Business. Retrieved from: https://www.canadianbusiness.com/blogs-andcomment/reviewed-the-wealthy-barber-returns/

McChesney, R. (2000). "Introduction: The Media/Democracy Paradox." In Rich Media, Poor Democracy: Communication Politics in Dubious Times. New York: The New York Press.

McGugan, Ian. (2015). David Chilton's rise from the wealthy barber to the wealthy dragon. The Globe and Mail. Retrieved from: https://www.theglobeandmail.com/report-on-business/careers/careersleadership/david-chiltons-rise-from-the-wealthy-barber-to-the-wealthydragon/article22612138/

Mosco, Vincent. (2009). The political economy of communication. Thousand Oaks, CA: Sage Publications.

Nawotka, Ed. (2018). Canadian publishing in 2018. Publisher's Weekly. Retrieved from: https://www.publishersweekly.com/pw/bytopic/international/international-book-news/article/77992-canadianpublishing-in-2018.htm

New Brunswick Arts Board. (2019). Literary arts. Retrieved from: https://artsnb.ca/web/wpcontent/uploads/2019/07/Critères Catégorie Criteria.pdf

Newfoundland and Labrador Arts Council. (2019). Professional project grants program. Retrieved from: http://www.nlac.ca/grants/index.htm

NWT Arts Council. (2019). NWT Arts Council funding guidelines. Retrieved from: https://www.nwtartscouncil.ca/forms/NWTAC-CATNO-2019-guidelineslignes.pdf

Ontario Arts Council, (2020). Recommender grants for writers. Retrieved from: http://www.arts.on.ca/grants/recommender-grants-for-writers 
Phillips, N. and Hardy, C. (2002). Discourse analysis: investigating processes of social construction. London: Sage.

Raboy, M., Bernier, I., Sauvageau, F., \& Atkinson, D. (1994). Cultural development and the open economy: A democratic issue and a challenge to public policy. Canadian Journal of Communication, 19(3). doi:https://doi.org/10.22230/cjc.1994v19n3a822

Samson, J. (2018). Self-publishing for Canadians. Ariesrising Media.

Shoesmith, J. (2013). A Death Greatly Exaggerated: Canada's Thriving Small and Fine Press. Toronto: Thomas Fisher Rare Book Library, University of Toronto.

Silver, E. (2017). How to self-publish. Toronto: The Writer's Union of Canada.

Vanity Publishing (2009). Vanity publishing advice and warning. Retrieved from: http://www.vanitypublishing.info 